\title{
Pharmacokinetics and Safety of an Intravitreal
} Humanized Anti-VEGF-A Monoclonal Antibody (PRO-169), a Biosimilar Candidate to Bevacizumab

\author{
Patricia Muñoz-Villegas (1) \\ Alejandra Sanchez-Rios' \\ Mayra G Quinonez- \\ Alvarado ${ }^{2}$ \\ Oscar Olvera-Montaño (iD) \\ Juan D Quintana-Hau² \\ Leopoldo Baiza-Duran' \\ 'Medical Affairs Department, \\ Laboratorios Sophia, S.A. de C.V., \\ Zapopan, Jalisco, México; ${ }^{2}$ Research and \\ Development Department (CIS), \\ Zapopan, Jalisco, México
}

\begin{abstract}
Background: PRO-169 is a biosimilar candidate to bevacizumab (BEV), a monoclonal antibody $(\mathrm{mAb})$ that inhibits vascular endothelial growth factor-A (VEGF-A) developed for intravitreal use. The current study demonstrates the intraocular pharmacokinetics (PK) of PRO-169 and its safety using New Zealand white (NZW) rabbits.

Methods: Intraocular concentration was evaluated in thirty-six rabbits at 1h, 1, 2, 5, 14 and 30 days after a single bilateral injection of PRO-169 or BEV $(1.25 \mathrm{mg} / 0.05 \mathrm{~mL})$. In a secondary experiment, safety was evaluated after three consecutive unilateral injections at 30-day intervals in twenty-four rabbits (PRO-169: $1.25 \mathrm{mg} / 0.05 \mathrm{~mL}$ or ranibizumab [RZB]: $0.5 \mathrm{mg} / 0.05 \mathrm{~mL}$ ), by liver-associated enzymes (LAE), ophthalmological examination and adverse event (AE) incidence. Primary endpoints were vitreous maximum concentration $\left(\mathrm{C}_{\max }\right)$, time to attain maximum concentration $\left(\mathrm{t}_{\max }\right)$, area under curve $\left(\mathrm{AUC}_{0-\mathrm{t}}\right)$, half-life $\left(\mathrm{t}_{1 /}\right.$ 2) and LAE. Secondary endpoints included aqueous humor (AH) and plasma pharmacokinetics, clinical examination and AEs.
\end{abstract}

Results: The $\mathrm{C}_{\max }$ in the vitreous was $593.75 \pm 45.63$ (PRO-169) vs $644.79 \pm 62.65 \mu \mathrm{g} / \mathrm{mL}$ (BEV) $(\mathrm{p}=0.136) . \mathrm{T}_{\max }$ was $0.53 \pm 0.82$ vs $0.85 \pm 0.73$ days $(\mathrm{p}=0.330)$. The $\mathrm{AUC}_{0-\mathrm{t}}$ was $3837.72 \pm 465.91$ vs $4247.31 \pm 93.99$ days $* \mu \mathrm{g} / \mathrm{mL}(\mathrm{p}=0.052)$ and the half-life was $4.99 \pm$ 0.89 vs $5.18 \pm 0.88$ days $(\mathrm{p}=0.711)$. LAEs were normal in $92 \%$ of NZW rabbits; no differences between groups were observed $(\mathrm{p}>0.05)$. The AH and plasma PKs were also similar. Finally, clinical examinations found no alterations. AEs were observed in $25 \%$ of PRO-169 rabbits, without differences vs RZB ( $\mathrm{p}=0.399)$.

Conclusion: PRO-169 can be efficiently diffused and distributed in ocular compartments, showing vitreous pharmacokinetics analogous to BEV. The safety experiment did not find evidence of clinical alterations from a repeated injection of PRO-169. These results provide scientific justification supporting that PRO-169 should be evaluated in future clinical trials to confirm its safety and efficacy.

Keywords: bevacizumab, pharmacokinetics, ranibizumab, safety, vascular endothelial growth factor

\section{Introduction}

Vascular endothelial growth factor (VEGF) promotes angiogenesis and neovascularization, regulating vascular differentiation and permeability. Its presence is necessary to maintain the normal functions of the eye, yet it can be harmful when it is overproduced, as it happens in diseases whose pathophysiology is based on
Correspondence: Patricia Muñoz-Villegas Medical Affairs Department, Laboratorios Sophia, S.A. de C.V., Paseo del Norte 5255, Guadalajara Technology Park. Zapopan, 45010, Jalisco, México Email patricia.munoz@sophia.com.mx 
neovascularization of the retina. To inhibit VEGF, many anti-VEGF agents have been developed, and their use has increased dramatically over the last decade. Conditions such as diabetic macular edema (DME), age-related macular degeneration (AMD), myopic choroidal neovascular membrane (MCNM), and retinal vein occlusion (RVO) require the administration of multiple intravitreal injections of anti-VEGF agents, to treat the altered blood vessels that grow in the choroid and trespass towards the retina potentially causing vision loss. The frequent dosing scheme required to treat these diseases represent a significant social and economic burden on patients; specially in developing countries.

IgG-based monoclonal antibody $(\mathrm{mAb})$ therapeutics consist of a Fab region, which binds to the intended target and an $\mathrm{Fc}$ region, which carries out effector functions. The binding of Fcy receptors for the Fc region leads to activation or deactivation of the immune system, and this interaction is considered important for the mechanism of action of many mAbs. ${ }^{1,2}$ This can also be an important safety consideration for IgG-based therapeutics. Additionally, the $\mathrm{Fc}$ region, via binding to the neonatal $\mathrm{Fc}$ receptor ( $\mathrm{FcRn}$ ) regulates the serum half-life of mAbs. ${ }^{3}$ FcRn acts as an immune receptor by interacting with and facilitating antigen presentation of peptides derived from IgG immune complex. ${ }^{1,4}$

Bevacizumab (BEV) is a humanized $\mathrm{mAb}$ (IgG1) that targets the VEGF-A to inhibit angiogenesis approved by the Food and Drug Administration (FDA) for metastatic colorectal cancer. It has also been used extensively as an off-label intravitreal treatment for many neovascular related retinal conditions. ${ }^{5}$ PRO-169 is a biosimilar candidate to $\mathrm{BEV}$, it is structurally similar and has target specificity like BEV does, but it was developed for intravitreal use. ${ }^{6,7}$ PRO-169 has been determined to be consistent with historical data such as quality, charge of heterogeneity, purity, structure, and binding affinity of commercially available BEV. ${ }^{6}$

Biosimilars are biologic medicines created to be highly similar to an approved biologic reference product developed by an originator company. ${ }^{8,9}$ However, since the manufacturing process of the original product is not disclosed, the potential differences in this procedure may translate in some differences in the biosimilar; therefore, the quality attributes of a biosimilar are not identical to those of the reference product. Comparable quality, safety and efficacy to those of a reference product must be evaluated and evidenced in a biosimilar biotechnological product. ${ }^{10}$ Some of the attributes assessed to demonstrate this similarity are structure, physicochemical and biological properties. For mAbs, biological antigen binding affinity and specificity, including isoelectric point, charge variant content, glycan structure, antigen binding, Fc $\gamma \mathrm{R}$ binding, and FcRn binding, should be comparable. ${ }^{11-13}$ In addition to the study of physicochemical and biological characteristics, biosimilars are usually subjected to in vitro and/or in vivo non-clinical and clinical studies to ensure there are no clinically meaningful differences to that of the reference medication. ${ }^{11,13}$

Since experimental and clinical studies have evaluated the adverse events (AEs) of BEV intravitreal injections, too few studies have reported the effects of BEV on distant organs and serum levels of VEGF. Intravitreal BEV not only may escape from the blood-retinal barrier and enter the general circulation, but also may be disseminated to distant organs. ${ }^{5,14,15}$

On the other hand, ranibizumab (RZB) is a monoclonal antibody Fab fragment developed for intravitreal injection and is currently approved as treatment for wet AMD, RVO, DME, DR and myopic choroidal neovascularization $(\mathrm{CNV})$. This is therefore the gold standard within this family of medications for such indications and was consequently chosen to serve as the active comparator in the safety experiment. Ranibizumab is a safe product, with broadly studied efficacy and safety, but presents an important economic burden on patients, indirectly promoting a decreased adherence to treatment.

In summary, similar inhibitory effects on angiogenesis between PRO-169 and BEV have been demonstrated in an in vivo preclinical study; PRO-169 has proven to have the same effectiveness in reducing the retinal thickness and fluorescein leakage area in a CNV rhesus monkey model. ${ }^{7}$ Also, PRO-169 has demonstrated to be nontoxic to the retina at the $1.25 \mathrm{mg}$ dose tested in NZW rabbit eyes. ${ }^{6}$ Here, we report the results of the intraocular pharmacokinetics profile after a single intravitreal injection of PRO169 and, in order to ensure that PRO-169 is safe after repeated injections, three consecutive intravitreal injections were administered at 30-days intervals in a second experiment. Together, these results comprise the scientific justification supporting that PRO-169 treatment should be evaluated in future clinical trials to confirm its safety and efficacy in the treatment of retinal neovascularization diseases. The purpose of the study was to investigate the 
pharmacokinetics of PRO-169. In addition, we also assessed its safety versus ranibizumab in NZW rabbits.

\section{Methods}

All procedures adhered to the guidelines from the ARVO Statement for the Use of Animals in Ophthalmic and Vision Research, and the approval was obtained from Institutional Animal Care and Use Committee of Laboratorios Sophia, S.A. de C.V. (CICUALLS).

\section{Pharmacokinetics in NZW Rabbits}

A total of thirty-six 2-4 months of age male NZW rabbits weighing between 2.0 and $3.0 \mathrm{~kg}$ were acclimatized for at least three weeks before the experiment under a 12/12hour light/dark cycle with free access to food and water. The intravitreal injection technique was described on previous published works. ${ }^{5,6}$ Briefly, before the bilateral injection, the animals were anesthetized with a mix of xylazine hydrochloride/ketamine hydrochloride $(10 \mathrm{mg} /$ $\mathrm{Kg} / \mathrm{BW} / 30 \mathrm{mg} / \mathrm{Kg} / \mathrm{BW}, \quad$ PROCIN $^{\circledR}$ and ANESKET $^{\circledR}$ VET, Pisa, Hidalgo, Mexico). A 30-gauge needle attached to a syringe containing test article (PRO-169, Laboratorios Sophia, S.A. de C.V. by KBI Biopharma) or BEV (Avastin $^{\circledR}$, Genentech Inc, San Francisco, CA, USA), both $1.25 \mathrm{mg} / 0.05 \mathrm{~mL}$, was used during the injection. After the intervention, a prophylactic broad-spectrum antibiotic eye drop was applied (ciprofloxacin 0.3\%, Sophixin $^{\circledR}$ Ofteno, Laboratorios Sophia, S.A. de C.V., Zapopan, Jalisco, Mexico) QID for seven days. Eyes were monitored for signs of inflammation and general health was evaluated daily. Before sacrifice, every animal was anesthetized with the same technique described previously and blood samples were collected into $\mathrm{BD}$ Vacutainer $^{\circledR}$ heparin tubes (Franklin Lakes, NJ). Blood samples were centrifuged at $1200 \mathrm{~g}$ for 10 minutes and plasma was collected and stored under $-80^{\circ} \mathrm{C}$ temperature. Three rabbits were euthanized at each of the following timepoints: $1 \mathrm{~h}, 1,2,5,14$ and 30 days through intravenous injection of $100 \mathrm{mg} / \mathrm{Kg} / \mathrm{BW}$ of pentobarbital (Doléthal ${ }^{\circledR}$, Vétoquinol, SA de CV, CDMX, Mexico). After sacrifice, and before enucleation, the aqueous humor (AH) of each eye was withdrawn into a syringe. The $\mathrm{AH}$ was immediately frozen at $-80^{\circ} \mathrm{C}$ until tested. Both eyeballs were immediately enucleated and frozen. The vitreous humor (VH) was obtained following a previously published method. ${ }^{16}$ Frozen vitreous was then completely extracted from the eye and was kept frozen at $-80^{\circ} \mathrm{C}$ until analysis.
PRO-169 and BEV concentrations in the VH, $\mathrm{AH}$, and plasma were determined by surface plasmon resonance (SPR), the assay was performed on a Biacore ${ }^{\circledR}$ T200 System using a Biacore amino coupling kit to immobilize VEGF. ${ }^{17}$ The lower limit of quantification (LLOQ) of this method was $3.333,0.625$ and $0.250 \mu \mathrm{g} / \mathrm{mL}$ for $\mathrm{VH}, \mathrm{AH}$ and plasma, respectively, meanwhile the upper limit of quantification (ULOQ) was 76.667, 9.000, and $1.400 \mu \mathrm{g}$ / $\mathrm{mL}$. For as the analyte, several concentrations of PRO-169 and $\mathrm{BEV}$ were injected over the flow cell at a flow rate of $30 \mu \mathrm{L} / \mathrm{min}$ at $25^{\circ} \mathrm{C}$. Each was serially diluted and analyzed against a Series S Sensor Chip CM5 immobilized with VEGF165 at a signal target. The wizard immobilization was $1500 \mathrm{RU}\left(1 \mathrm{RU} \approx 1 \mathrm{pg} / \mathrm{mm}^{2}\right)$. The SPR method was validated before samples were analyzed. The validation of the method included selectivity and specificity (exempt of interferences for other components), repeatability (measurement of precision), reproducibility (the degree of agreement between the results of experiments conducted), accuracy (the closeness of a result to the true value), and stability of the analyte in the matrix (sample quality variation dependent on time and temperature). The analytical response of the samples was less than $20 \%$ of the average of the analytical response of the samples added to LLOQ. To evaluate accuracy and precision, five different concentrations $(3.333,8.667,30.000,40.000$, and $76.667 \mu \mathrm{g} / \mathrm{mL}$ for $\mathrm{VH}, 0.700,1.100,4.000,4.500$, and $9.000 \mu \mathrm{g} / \mathrm{mL}$ for $\mathrm{AH}$, and $0.250,0.650,0.800,0.850$ and $1.400 \mu \mathrm{g} / \mathrm{mL}$ for plasma) of PRO-169 and BEV were added into the different samples from controls. ${ }^{18}$ Additionally, hemolyzed plasma was evaluated to eliminate/minimize any significant interference. Concentrations of PRO-169 and BEV in samples were calculated from equilibrium binding $\left(R_{e q}\right)$ values at flow setting.

\section{Safety Evaluations}

A total of twenty-four NZW rabbits were included in this experiment. Inclusion criteria were healthy rabbits aged 2 to 3 months, weighing between 2.0 and $3.0 \mathrm{~kg}$. All rabbits were acclimatized for at least 7 days before the experiment under a 12/12-hour light/dark cycle with free access to food and water, during which general health was assessed daily. An ophthalmic eligibility screening with slit lamp (Luxvision ${ }^{\circledR}$, Class I Type B, Doral FL, USA) examination and fluorescein staining (corneal and conjunctival) was performed to ensure there was no presence of secretion, conjunctival hyperemia, corneal or conjunctival lacerations, corneal degeneration or neovascularization, cataract, 
or any pathological findings such as retinal detachment, tears or neovascularization evaluated through indirect fundoscopy performed with a $78 \mathrm{D}$ lens (Ocular Instruments, Bellevue, WA, USA). Slit lamp and indirect funduscopic examinations were performed on all eyes before the study began, and was repeated at least 7 times after each intravitreal injection, on days $2,3,4,8,15,22,29,33,34,35,39$, $46,53,60,64,65,66,70,77,84$ and 91. Intravitreal injections took place on days 1, 32, and 63 (a total of 4 NZW rabbits per group). The intravitreal injection technique was the same described on PK evaluation. On this experiment, positive control was ranibizumab (RZB, Lucentis ${ }^{\circledR}$, Novartis Pharmaceuticals, Genentech Inc, San Francisco, CA, USA), a commercially available mAb approved for intravitreal injection. The injections were administered to right (OD) eyes for both PRO-169 $(1.25 \mathrm{mg} / 0.05 \mathrm{~mL})$ and RZB $(0.5 \mathrm{mg} / 0.05 \mathrm{~mL})$ groups. On days 31,62 , and 93 , prior to sacrifice and after anesthesia as described for the PK experiment, blood samples were collected into BD Vacutainer ${ }^{\circledR}$ tubes (Franklin Lakes, NJ), for LAE evaluations in serum.

Safety was evaluated through changes on fluorescein corneal and conjunctival staining, conjunctival hyperemia, conjunctival edema, eye watering, the incidence of adverse events (AEs) and LAE (ALT, AST, total and direct (conjugated) bilirubin, total proteins, albumin and, gammaglutamyl transferase). Potential safety risk of LAE were identified based on values that fell outside of normal reference ranges in rabbits. ${ }^{19-22}$ All experimental animals were subjected to necropsy after sacrifice. Macroscopic and microscopic evaluation of the following organs was performed: trachea, lungs, heart, liver, kidney, spleen, stomach, intestine and brain.

\section{Statistical Analyses}

PK was obtained using a parallel non-compartment model. Parameters including $\mathrm{C}_{\max }, \mathrm{t}_{1 / 2}, \mathrm{AUC}_{0-\mathrm{t}}, \mathrm{AUC}_{0-\infty}$, and $\mathrm{t}_{\max }$ were analyzed using Phoenix WinNolin ${ }^{\circledR} 8.2$ (Pharsight, a Certara Company, St Louis, MO) by fitting the data to the linear-up/log-down model. ${ }^{5}$ The experimental data were plotted in a semi-logarithmic plot using GraphPad Prism 4.0 (GraphPad Prism software Inc, San Diego, CA) logarithm of intravitreal concentration vs time. Regarding bioavailability evaluation, the percentage of ratio from geometric means of each parameter (on logarithmic scale), and the $90 \%$ confidence interval (CI) with a distribution of two-tailed Student's $t$-test were calculated. If the CI was within the acceptance ranges established by international guidelines (90\% CI, [80-125\%]), it was considered within the range of bioequivalence. Next, Schuirmann's two one-side test (TOST) approach was performed to test equivalence $\left(\delta_{\mathrm{I}}=0.8\right)$. In addition, bioavailability and non-inferiority were equivalent in the absence of $\geq 20 \%$ difference in $\mathrm{C}_{\max }$ and $\mathrm{AUC}_{0-\mathrm{t}}$.

Analyses of safety data were carried out using SPSS 19.0 software for Windows (SPSS Inc., Chicago, IL, USA). Microsoft ${ }^{\circledR}$ Office Excel 2016 was used for data processing. Statistical significance was determined by Mann-Whitney test for continuous data, and Chi square test or Fisher's exact test for categorical data. All statistical analyses performed in this study were with $p$ values $\leq$ 0.05 considered statistically significant.

\section{Results}

\section{Pharmacokinetics}

Data were obtained from 72 eyes of 36 NZW rabbits. No signs of ocular inflammation or adverse events were observed. PRO-169 and BEV achieved a peak concentration in the vitreous humor at $1 \mathrm{hr}$ for PRO-169 and 1 day for $\operatorname{BEV}(540.52 \pm 108.95 \mu \mathrm{g} / \mathrm{mL}$ vs $563.16 \pm 83.75 \mu \mathrm{g} /$ $\mathrm{mL}, \mathrm{p}>0.05)$. Vitreous concentration declines with a halflife of $4.991 \pm 0.89$ days versus $5.182 \pm 0.88$ days for PRO-169 and BEV, respectively, no significant differences were observed $(p=0.711)$. No vitreous concentrations of PRO-169 or BEV were detected beyond 30 days $(<3.33$ $\mu \mathrm{g} / \mathrm{mL})$ post-injection.

The VH pharmacokinetics profile was similar between PRO-169 and BEV. The $\mathrm{C}_{\max }$ for PRO-169 was $593.75 \pm$ $45.63 \mu \mathrm{g} / \mathrm{mL}$ versus $644.79 \pm 62.66 \mu \mathrm{g} / \mathrm{mL}$ for $\mathrm{BEV}(\mathrm{p}=$ 0.136). The ratio of means was $92.21,90 \%$ CI [84.22-100.96], $\mathrm{p}=0.009$ (TOST, $\mathrm{p}<0.05$ ). The $\mathrm{AUC}_{0-\mathrm{t}}$ was $3837.72 \pm 465.91$ days $* \mu \mathrm{g} / \mathrm{mL}$ for PRO-169 and 4247.31 \pm 93.99 days $* \mu \mathrm{g} / \mathrm{mL}$ for $\mathrm{BEV}(\mathrm{p}=0.053)$. The ratio of means was 89.85, 90\% CI, [82.26-98.13], $\mathrm{p}=0.019$ (TOST, $\mathrm{p}<0.05)$. The $\mathrm{AUC}_{0-\mathrm{t}}$ for PRO-169 and $\mathrm{BEV}$ was higher than $80 \%$ in relation to the $\mathrm{AUC}_{0-\infty}(4495.83 \pm 683.41$ days* $\mu \mathrm{g} / \mathrm{mL}$ vs $4996.89 \pm 212.41$ days* $\mu \mathrm{g} / \mathrm{mL})$. The $t_{\max }$ was similar between PRO-169 and $\operatorname{BEV~}(0.53 \pm 0.82$ days vs $0.85 \pm 0.73$ days), without differences between treatments ( $p=0.330$ ), see Table 1. PRO-169 compared to BEV meets the similarity criteria in concentrations, ANOVA test, bioavailability (ratio of means and 90\% CI), and non-inferiority with the TOST, for the $\mathrm{C}_{\max }$ and $\mathrm{AUC}_{0-\mathrm{t}}$.

In the $\mathrm{AH}$, both mAbs reached a peak concentration of $67.07 \pm 70.5 \mu \mathrm{g} / \mathrm{mL}$ for PRO-169 versus $80.63 \pm 53.63$ 
$\mu \mathrm{g} / \mathrm{mL}$ for BEV $1 \mathrm{hr}$ after the drug administration. Elimination of PRO-169 and BEV from AH and plasma paralleled that found in the $\mathrm{VH}$, with half-life values of $6.59 \pm 1.17$ days, and $7.65 \pm 1.98$ days, respectively. The $\mathrm{C}_{\max }$ was $63.35 \pm 53.3 \mu \mathrm{g} / \mathrm{mL}$ for PRO-169 and $89.15 \pm$ $41.91 \mu \mathrm{g} / \mathrm{mL}$ in BEV. The time to attain this concentration was $1.01 \pm 0.88$ days in PRO-169 and $0.36 \pm 0.49$ days in BEV. The $\mathrm{AUC}_{0-\mathrm{t}}$ was $284.16 \pm 67.23$ days* $\mu \mathrm{g} / \mathrm{mL}$ in PRO-169 and $320.62 \pm 21.83$ days* $\mu \mathrm{g} / \mathrm{mL}$ for BEV. The change in concentration over time for PRO-169 and BEV in $\mathrm{VH}$ and $\mathrm{AH}$ after the single bilateral intravitreal injection of $1.25 \mathrm{mg} / 0.05 \mathrm{~mL} \mathrm{mAb}$, is illustrated in Figure 1 . The maximum concentration of PRO-169 attained in the $\mathrm{AH}$ was $10.67 \%$ of the maximum concentration in $\mathrm{VH}$ versus $13.83 \%$ for BEV. Considering the half-life, the total exposure of $\mathrm{AH}$ to $\mathrm{PRO}-169$ and $\mathrm{BEV}$ were $7.14 \%$ and $7.64 \%$ of that of the $\mathrm{VH}$, respectively, see Table 1 .

Finally, the $\mathrm{C}_{\max }$ in plasma was $22.05 \pm 24.5 \mu \mathrm{g} / \mathrm{mL}$ for PRO-169 and $15.30 \pm 6.6 \mu \mathrm{g} / \mathrm{mL}$ in BEV. The time to attain this concentration was $3.00 \pm 1.73$ days in PRO-169 and $5.67 \pm 7.23$ days in BEV. The $\mathrm{AUC}_{0-\mathrm{t}}$ was $268.67 \pm$ 270.45 days $* \mu \mathrm{g} / \mathrm{mL}$ in PRO-169 and $145.28 \pm 86.57$ days* $\mu \mathrm{g} / \mathrm{mL}$ for BEV. No plasma concentrations of PRO-169 or BEV were detected before 24 hours $(<0.250$ $\mu \mathrm{g} / \mathrm{mL}$ ) post-injection. The maximum plasma concentration of PRO- 169 was $3.71 \%$ of the maximum VH concentration versus $2.37 \%$ for $\mathrm{BEV}$.

\section{Safety}

Safety was evaluated in a second experiment where PRO169 was compared to RZB, the commercially available approved $\mathrm{mAb}$ for intravitreal administration. As expected for PRO-169, LAE were within normal ranges in $92 \%$ of NZW rabbits. ALT and AST elevations were observed in one rabbit (PRO-169 group). For ALT, a value exceeding the upper threshold at 5.6 times limit reference was obtained, while AST tested 9.3 times over the limit reference. No safety additional issues were raised. These values were considered outliers, removed from the analyses, and reported as an AE. No significant differences between PRO-169 and RZB were observed in all liver function parameters as shown Table 2 (Mann-Whitney $U$-test, $\mathrm{p}>0.05$ ). The laboratory results were maintained within normal reference ranges in both treatments.

All of examined eyes exposed to both PRO-169 and RZB treatments presented absence of any pathological condition, active or inactive after the three successive intravitreal injections (until day 91). Corneal and

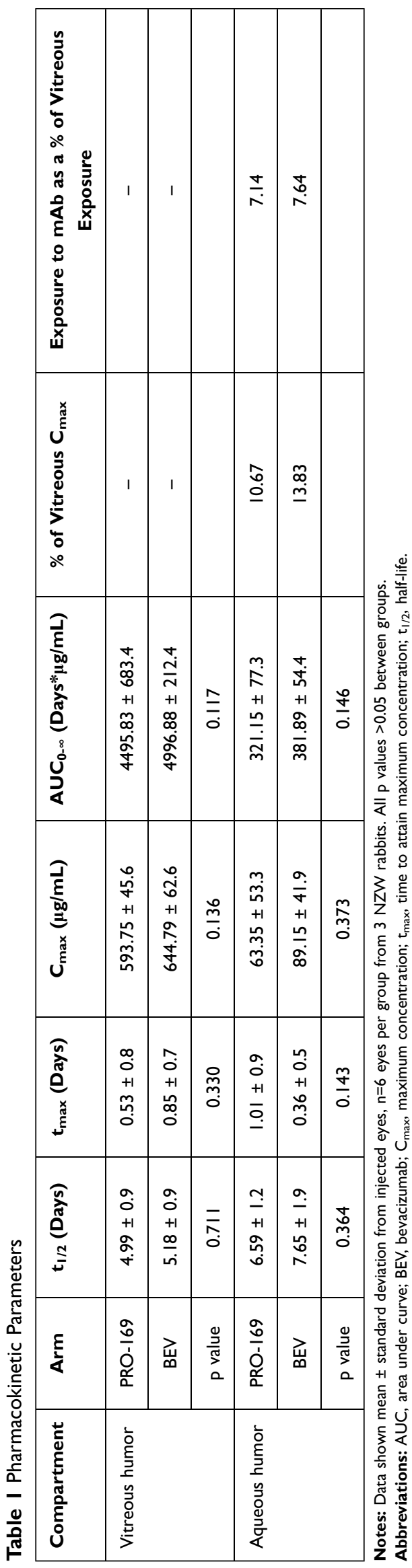




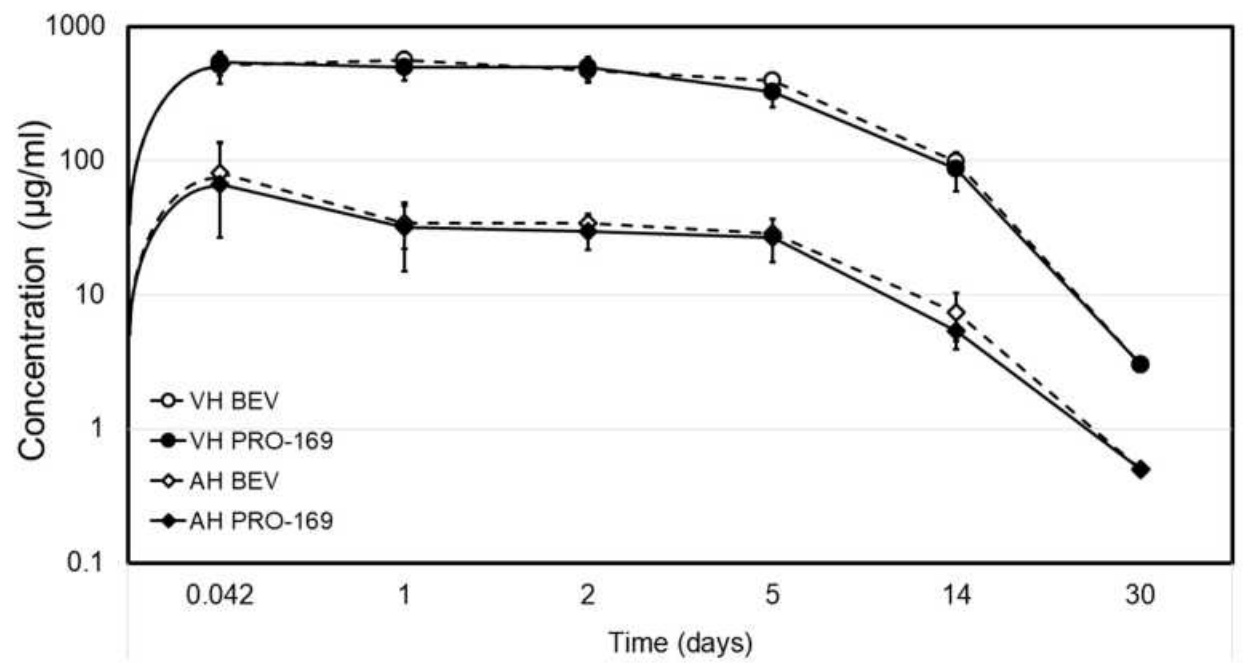

Figure I PRO- 169 (black figures) and bevacizumab (white figures) concentration in the vitreous humor (VH) and aqueous humor (AH) after intravitreal injection of I.25 mg/ $0.05 \mathrm{~mL}$ of each $\mathrm{mAb}$. Samples was taken from the vitreous and aqueous humor of injected eyes, mean \pm standard deviation.

conjunctival fluorescein staining was graded as absent (grade 0) for all NZW rabbits in both treatments on baseline and during the follow-up period. Similar findings between PRO-169 and RZB were observed in the analysis of conjunctival hyperemia. After the second injection, one rabbit in PRO-169 and two in RZB groups presented moderate hyperemia (Pearson Chi-square test, $\mathrm{p}=0.311$ ), the remaining rabbits were reported to have trace to mild hyperemia. On day 33, one rabbit in the PRO-169 group presented a mild conjunctival edema, and an increase in tear level and tear meniscus curvature; however, these findings were not statistically different nor clinically significant between treatments (Fisher exact test, $\mathrm{p}=1.000$ ). Additionally, no subjects presented cataract formation associated to either $\mathrm{mAb}$.

Finally, 7 AEs were observed in 5 NZW rabbits (20.83\%). The number of cases which presented signs of ocular inflammation did not amount to any statistically or clinically significant difference as compared to the control group or between intervention groups. The cases classified as presenting inflammation included one or more of the following signs: conjunctival hyperemia, anterior chamber cellularity, posterior synechiae, congestive iris, or transpupillary membrane formation. One rabbit (PRO-169) died

Table 2 Liver Function Panel After Intravitreal Injections

\begin{tabular}{|c|c|c|c|c|c|c|c|c|}
\hline Injections & Arm & $\begin{array}{c}\text { ALT, U/L } \\
(\mathbf{4 8 . 0 - 8 0 . 0 )}\end{array}$ & $\begin{array}{c}\text { AST, U/L } \\
(|4.0-| \mid 3.0)\end{array}$ & $\begin{array}{c}\text { TB, mg/dl } \\
(0.0-0.1)\end{array}$ & $\begin{array}{c}\text { DB, mg/dl } \\
(0.0-0.1)\end{array}$ & $\begin{array}{c}\text { Proteins, g/dl } \\
\quad(5.4-7.5)\end{array}$ & $\begin{array}{c}\text { Albumin, g/dl } \\
\quad(3.6-5.7)\end{array}$ & $\begin{array}{c}\text { GGT, U/L } \\
(5.0-8.0)\end{array}$ \\
\hline \multirow[t]{2}{*}{ I } & PRO- 169 & $61.75 \pm 10.44$ & $53.00 \pm 9.93$ & $0.13 \pm 0.05$ & $0.03 \pm 0.05$ & $5.50 \pm 0.26$ & $5.35 \pm 0.24$ & $6.25 \pm 1.71$ \\
\hline & RZB & $64.25 \pm 22.29$ & $54.00 \pm 17.42$ & $0.13 \pm 0.05$ & $0.05 \pm 0.06$ & $5.55 \pm 0.19$ & $5.35 \pm 0.19$ & $6.50 \pm 1.29$ \\
\hline \multirow[t]{2}{*}{2} & PRO- 169 & $68.00 \pm 10.07$ & $42.75 \pm 5.74$ & $0.10 \pm 0.00$ & $0.01 \pm 0.01$ & $5.63 \pm 0.13$ & $5.40 \pm 0.22$ & $7.75 \pm 1.26$ \\
\hline & RZB & $53.00 \pm 18.67$ & $38.75 \pm 10.14$ & $0.05 \pm 0.06$ & $0.01 \pm 0.01$ & $5.55 \pm 0.24$ & $5.15 \pm 0.40$ & $7.50 \pm 3.11$ \\
\hline \multirow[t]{2}{*}{3} & PRO- 169 & $59.00 \pm 11.31$ & $74.00 \pm 18.39$ & $0.05 \pm 0.07$ & $0.01 \pm 0.01$ & $5.50 \pm 0.14$ & $5.20 \pm 0.00$ & $4.50 \pm 3.54$ \\
\hline & RZB & $45.00 \pm 16.46$ & $52.33 \pm 12.66$ & $0.03 \pm 0.06$ & $0.01 \pm 0.01$ & $5.37 \pm 0.25$ & $5.13 \pm 0.32$ & $5.67 \pm 1.53$ \\
\hline \multirow[t]{2}{*}{ Total } & PRO- 169 & $63.70 \pm 9.96$ & $53.10 \pm 15.04$ & $0.10 \pm 0.05$ & $0.01 \pm 0.03$ & $5.55 \pm 0.14$ & $5.34 \pm 0.20$ & $6.50 \pm 2.12$ \\
\hline & RZB & $54.91 \pm 19.33$ & $48.00 \pm 14.43$ & $0.07 \pm 0.06$ & $0.02 \pm 0.04$ & $5.50 \pm 0.22$ & $5.21 \pm 0.32$ & $6.63 \pm 2.11$ \\
\hline
\end{tabular}

Notes: Mean values \pm SD from 12 NZW rabbit's per group. In all comparisons, $p>0.05$ (Mann-Whitney U-test).

Abbreviations: ALT, alanine transferase; AST, aspartate transferase; DB, direct (conjugated) bilirubin; GGT, gamma-glutamyl transferase; RZB, ranibizumab; SD, standard deviation; TB, total bilirubin. 
Table 3 Adverse Events

\begin{tabular}{|l|c|c|c|}
\hline Treatment & AEs & Incidence & $\begin{array}{c}\text { Experimental } \\
\text { Day }\end{array}$ \\
\hline PRO-169 & $\begin{array}{c}\text { Intraocular } \\
\text { inflammation }\end{array}$ & $8.3 \%(1 / 12)$ & $33-53$ \\
\cline { 2 - 4 } & $\begin{array}{c}\text { Vitreous } \\
\text { detachment }\end{array}$ & $8.3 \%(1 / 12)$ & $16-18$ \\
\cline { 2 - 4 } & Death & $8.3 \%(1 / 12)$ & 92 \\
\cline { 2 - 4 } & $\begin{array}{c}\text { ALT and AST } \\
\text { elevation }\end{array}$ & $8.3 \%(1 / 12)$ & 93 \\
\hline Ranibizumab & $\begin{array}{c}\text { Vitreous } \\
\text { detachment }\end{array}$ & $8.3 \%(1 / 12)$ & 29 \\
\cline { 2 - 4 } & Cataract formation & $8.3 \%(1 / 12)$ & $39-91$ \\
\cline { 2 - 4 } & $\begin{array}{c}\text { Intraocular } \\
\text { inflammation }\end{array}$ & $8.3 \%(1 / / 2)$ & $33-91$ \\
\hline
\end{tabular}

Notes: Incidence of adverse events (AEs) in injected eyes. For PRO-169 4 AEs vs 3 AEs for ranibizumab, in a total of 5 rabbits $(20.8 \%, 5 / 24)$.

after the $3^{\text {rd }}$ injection (during the follow-up period, day 92). However, it did not present any clinical finding that suggested illness prior to its death, and the necropsy revealed that was non-related to treatment. The incidence of AEs was similar between PRO-169 and RZB (Pearson Chi-square test, $\mathrm{p}=0.399$ ), see Table 3.

Necropsy results of the rest of the animals showed no lesion or alteration specific to any particular disease or pathological process.

\section{Discussion}

VEGF is a signaling protein involved in the initiation of vasculogenesis and angiogenesis. As a result of VEGF overexpression, retinal neovascularization may occur. Bevacizumab is an $\mathrm{mAb}$ designed to directly bind to VEGF to prevent its interaction with VEGF receptors on the surface of endothelial cells, and thereby may inhibit its angiogenic activity. ${ }^{23,24}$ After injected intravitreally, it is distributed to the ocular tissues, and this distribution depends on the ability of the drug to partition. ${ }^{25}$ IgGbased mAbs such as BEV consist of a Fab region, which binds to the intended target and an $\mathrm{Fc}$ region, which carries out effector functions. ${ }^{4}$ The binding of Fc $\gamma$ receptors such as FcRn conditions activation or deactivation of the immune system. Given the role of FcRn in reducing the rate of $\operatorname{IgG}$ elimination, it has been suggested that this receptor contributes to the severity and to the pathogenesis of humoral autoimmune conditions. ${ }^{13,26}$
Pharmacokinetics of intravitreally administered drugs determine the duration of ocular effect and the degree of systemic exposure, relevant for the selection of treatment regimens and systemic safety assurance. ${ }^{27}$ This is relevant for anti-VEGF drugs since depending on the selected molecule and the patient's response to treatment, injections may be performed as frequently as every month. In average, patients suffering from DME, AMD and RVO under either a pro re nata or a treat-and-extend antiangiogenic injection regime will require an average of 7 interventions during their first-year management. ${ }^{28,29}$ This multiple exposition to the molecule implies not only the great importance of counting with the required evaluations to assure comparability and therefore no efficacy and safety differences between the biosimilar PRO-169 and the reference product, but also the relevance of having a biosimilar option that may relieve social and economic burden on patients who require multiple applications of the drug. There are several studies on the cost-effectiveness of this kinds of therapies, as well as the comparison between the commercially available options and how patients' acquisitive power impacts their adherence to treatment. The cost of treatment with ranibizumab can amount to up to three times or more of that of bevacizumab in certain countries. $^{30-33}$

The purpose of the study was to investigate the PK and safety after intravitreal injections of PRO-169 in NZW rabbits. Previous characterization results for PRO-169 were comparable to those of BEV, meeting the acceptance criteria (80-125\%). ${ }^{6}$ Regarding the PK study, concentration in the target tissue, vitreous humor, showed no statistically significant difference for the studied variables $\mathrm{C}_{\max }$, $\mathrm{t}_{\max }$ and $\mathrm{AUC}_{0-\mathrm{t}}$ between PRO-169 and BEV (bevacizumab). Elimination of PRO-169 and BEV from the AH and plasma paralleled elimination from $\mathrm{VH}$, with half-life values of 6.59 and 7.65 days, respectively, similarly to previous results in Dutch Belted rabbits. ${ }^{5,15}$ In NZW rabbits, PRO-169 was still detectable in ocular tissues at day 14 after a single intravitreal dose, with the highest level in $\mathrm{VH}$.

Safety was also evaluated in a separate experiment, through LAEs, fluorescein staining, conjunctival hyperemia, conjunctival edema, eye watering and the incidence of adverse events compared to the approved intravitreal $\mathrm{mAb}$ ranibizumab. There are several available preclinical trials reporting on the safety of bevacizumab and other anti-VEGF products with a duration of one month of less. $^{34-39}$ Furthermore, the usual initial dose of 
bevacizumab and other anti-VEGF drugs is three monthly injections followed by dosing schemes based on either further spacing between administrations or imaging/clinical patient response. Therefore, we decided to use this initial dose time frame for this preclinical trial, lengthening the duration of other reported studies and applying more than one dose in two of the three included groups. Regarding the LAE evaluations, one rabbit (PRO-169 group) presented elevated transaminases which was considered an AE. In rabbits, hepatic ALT activity is lower than in other species and there is less organ specificity. AST is found in the liver, heart, skeletal muscle, kidney and pancreas with the highest activity in the liver and skeletal muscle. ${ }^{22}$ However, physical exertion or tissue damage during blood collection can elevate results and raised AST levels have been found after anesthesia in NZW rabbits. ${ }^{40}$ The unexpected ALT and AST elevations could be explained by the hepatic metabolism of anesthesia or as response to stress during physical restraint and manipulation, or after attempts at venous and arterial puncture. No statistically significant difference was found for any of the other clinical variables between PRO-169 and RZB.

In the PK study, after a single bilateral intravitreal injection of PRO-169 or BEV, no signs of ocular inflammation or adverse events were observed. However, in the safety experiment, after 3-successive unilateral intravitreal injections (at 30-days intervals), a total of 7 AEs were reported ( 4 for PRO-169, and 3 for RZB). Some of the adverse reactions observed were attributed to the intravitreal procedure such as cataract formation, posterior vitreous detachment and hyperemia (expected according to the manipulation pre and post procedure). ${ }^{41-43}$ Other findings considered expected adverse reactions to the product were intraocular inflammation. ${ }^{42-45}$ One rabbit died spontaneously (PRO-169); however, the necropsy concluded that this event was non-related to treatment. This death may be incidental or as result of stress, anesthesia, or housing; since the amount of time that elapsed postmortem until finding the corpse is not clear, microscopic evaluations were not performed since postmortem changes in tissues has occurred, but no macroscopic pathology was observed.

Biosimilars are developed and evaluated through a rigorous process involving analytical and functional studies. ${ }^{9,10,13}$ The antigen binding affinity and specificity of the biosimilar and the reference product should be comparable. ${ }^{11}$ Similarities in PK parameters of biosimilars have been evaluated in experimental animals, since comparable PK parameters should be confirmed. In the current study a good similarity of pharmacokinetic properties of BEV and PRO-169 biosimilar candidate was proven by analysis of undiluted, $25 \mathrm{mg} / \mathrm{mL}$ bevacizumab drug product solution after administration to a NZW rabbit model. This approach provides a comprehensive comparison of the BEV bioavailability properties.

No statistically significant difference was found for any of the analyzed clinical and VH PK variables, further contributing to the confirmation of PRO-169's comparability to the commercially available active comparators and proving its biosimilarity to such products for both pharmacokinetics and safety profiles in in vivo models.

The limitations of this study include the fact that the approach of this study included compartmental pharmacokinetics, therefore leaving out the analysis of the other ocular tissues such as ciliary body, choroid, and iris. Also, bevacizumab's commercial presentation lacks a robust number of published preclinical safety studies and since it is the same molecule as PRO-169, it would have provided valuable information if it had been included in the study as a third arm.

\section{Conclusion}

PRO-169 is vastly similar to BEV, it can efficiently diffuse and distribute in ocular compartments, with a vitreous humor pharmacokinetics profile analogous to BEVs. Previously published preclinical studies of PRO169 's efficacy; as well as the data obtained by biological characterization, pharmacokinetics study and safety profile, confirm that there are no meaningful differences between PRO-169 and its reference products in terms of its safety and efficacy. Future clinical trials to confirm its behavior in a clinical setting for the treatment of retinal neovascularization must be conducted.

\section{Abbreviations}

$\mathrm{AH}$, aqueous humor; $\mathrm{AUC}$, area under curve; $\mathrm{BEV}$, bevacizumab; $\mathrm{C}_{\max }$, maximum concentration; FcRn, neonatal Fc receptor; LAE, liver-associated enzymes; mAb, monoclonal antibody; NZW, New Zealand white; PK, pharmacokinetics; RZB, ranibizumab; SPR, surface plasmon resonance; $t_{1 / 2}$, half-life; $t_{\max }$, time to attain maximum concentration; VEGF, vascular endothelial growth factor; $\mathrm{VH}$, vitreous humor.

\section{Data Sharing Statement}

The datasets generated and analyzed during the current study are available in Open Science Framework (https:// $\underline{\text { osf.io) }}$ at DOI 10.17605/OSF.IO/ZP3B7. 


\section{Acknowledgment}

We thank Andrea Navarro-Sánchez for her technical assistance during the experiments.

\section{Author Contributions}

All named authors meet the International Committee of Medical Journal Editors (ICMJE) criteria for authorship for this article, take responsibility for the integrity of the work, and have given their approval for this version to be published. All authors made substantial contributions to conception and design, acquisition of data, or analysis and interpretation of data; took part in drafting the article or revising it critically for important intellectual content; agreed to submit to the current journal; gave final approval of the version to be published; and agree to be accountable for all aspects of the work.

\section{Disclosure}

This study was sponsored by Laboratorios Sophia, S.A. de C.V. (Zapopan, Jalisco, Mexico). MVP, SRA, OMO and BDL are employees of Laboratorios Sophia, S.A. de C.V., QAMG and QHJD are employees of Centro de Investigación Sophia (CIS). The sponsor provided support in the form of salaries for authors (MVP, SRA, OMO, and BDL), this does not alter our adherence to the Good Publication Practice guidelines for pharmaceutical companies (GPP3) polices on sharing data and materials. The authors report no other conflicts of interest in this work.

\section{References}

1. Pyzik M, Sand KMK, Hubbard JJ, Andersen JT, Sandlie I, Blumberg RS. The Neonatal Fc Receptor (FcRn): a misnomer? Front Immunol. 2019;10:1540.

2. Mancardi D, Daëron M. Fc receptors in immune responses. Ref Module Biomed Sci. 2014;B978-0-12-801238-3.00119-7.

3. Saxena A, Wu D. Advances in therapeutic Fc engineering - modulation of IgG-associated effector functions and serum half-life. Front Immunol. 2016;7:580. doi:10.3389/fimmu.2016.00580

4. Suzuki T, Ishii-Watabe A, Tada M, et al. Importance of neonatal FcR in regulating the serum half-life of therapeutic proteins containing the Fc domain of human IgG1: a comparative study of the affinity of monoclonal antibodies and Fc-fusion proteins to human neonatal FcR. J Immunol. 2010;184(4):1968-1976. doi:10.4049/ jimmunol.0903296

5. Bakri SJ, Snyder MR, Reid JM, Pulido JS, Singh RJ. Pharmacokinetics of intravitreal bevacizumab (Avastin). Ophthalmology. 2007;114(5):855-859. doi:10.1016/j. ophtha.2007.01.017

6. Baiza-Durán L, Sánchez-Ríos A, González-Barón J, et al. Safety and tolerability evaluation after repeated intravitreal injections of a humanized anti-VEGF-A monoclonal antibody (PRO-169) versus ranibizumab in New Zealand white rabbits. Int $J$ Retina Vitreous. 2020;6:32. doi:10.1186/s40942-020-00235-y
7. Olvera-Montaño O, Baiza-Duran L, Quintana-Hau JD, et al. Comparing the efficacy of an anti-human VEGF-a neutralizing antibody versus bevacizumab on a laser-induced Choroidal Neovascularization (CNV) rhesus monkey model. Drug Des Devel Ther. 2019;13:3813-3821. doi:10.2147/DDDT.S219350

8. Hanes V, Chow V, Pan Z, Markus R. A randomized, single-blind, single-dose study to assess the pharmacokinetic equivalence of the biosimilar ABP 215 and bevacizumab in healthy Japanese male subjects. Cancer Chemother Pharmacol. 2018;82(5):899-905. doi:10.1007/s00280-018-3695-4

9. Declerck P, Danesi R, Petersel D, Jacobs I. The language of biosimilars: clarification, definitions, and regulatory aspects. Drugs. 2017;77 (6):671-677. doi:10.1007/s40265-017-0717-1

10. Marini JC, Anderson M, Cai XY, et al. Systematic verification of bioanalytical similarity between a biosimilar and a reference biotherapeutic: committee recommendations for the development and validation of a single ligand-binding assay to support pharmacokinetic assessments. AAPS J. 2014;16(6):1149-1158.

11. Ishii-Watabe A, Kuwabara T. Biosimilarity assessment of biosimilar therapeutic monoclonal antibodies. Drug Metab Pharmacokinet. 2019;34(1):64-70. doi:10.1016/j.dmpk.2018.11.004

12. Arvinte T, Palais C, Poirier E, et al. Part 1: physicochemical characterization of bevacizumab in undiluted $25 \mathrm{mg} / \mathrm{mL}$ drug product solutions: comparison of originator with a biosimilar candidate. J Pharm Biomed Anal. 2019;175:112742. doi:10.1016/j. jpba.2019.06.039

13. Jacobs I, Petersel D, Shane LG, et al. Monoclonal antibody and fusion protein biosimilars across therapeutic areas: a systematic review of published evidence. BioDrugs. 2016;30(6):489-523.

14. Dinc E, Yildırım O, Necat Yilmaz S, et al. Intravitreal bevacizumab effects on VEGF levels in distant organs: an experimental study. Cutan Ocul Toxicol. 2014;33(4):275-282. doi:10.3109/ 15569527.2013.855227

15. Nomoto H, Shiraga F, Kuno N, et al. Pharmacokinetics of bevacizumab after topical, subconjunctival, and intravitreal administration in rabbits. Invest Ophthalmol Vis Sci. 2009;50(10):4807-4813. doi:10.1167/iovs.08-3148

16. Ahn SJ, Hong HK, Na YM, et al. Use of rabbit eyes in pharmacokinetic studies of intraocular drugs. J Vis Exp. 2016;113:53878.

17. Ohara K, Horibe T, Kohno M, Kawakami K. Characterization of antilytic peptide antibody: application for the detection of lytic-based hybrid peptide in serum samples. J Pept Sci. 2011;17 (7):493-498. doi:10.1002/psc.1349

18. Sinapis CI, Routsias JG, Sinapis AI, et al. Pharmacokinetics of intravitreal bevacizumab (Avastin ${ }^{\circledR}$ ) in rabbits. Clin Ophthalmol. 2011;5:697-704. doi:10.2147/OPTH.S19555

19. Hein J, Hartmann K. Labordiagnostische referenzbereiche bei Kaninchen, in reference ranges for laboratory parameters in rabbits. Tierarztl Prax Ausg $K$ Kleintiere Heimtiere. 2003;31:321-328.

20. Hewitt C, Innes D, Savory J, Wills M. Normal biochemical and hematological values in New Zealand white rabbits. Clin Chem. 1989;35(8):1777-1779.

21. Özkan C, Kaya A, Akgül Y. Normal values of haematological and some biochemical parameters in serum and urine of New Zealand white rabbits. World Rabbit Sci. 2012;20(4):253-259. doi:10.4995/ wrs.2012.1229

22. Benson K, Paul-Murphi J. Clinical pathology of the domestic rabbit. Acquisition and interpretation of samples. Vet Clin North Am. 1999;2 (3):539-551.

23. Mitchell P, Liew G, Gopinath B, Wong TY. Age-related macular degeneration. Lancet. 2018;392(10153):1147-1159.

24. Merz PR, Röckel N, Ballikaya S, Auffarth GU, Schmack I. Effects of ranibizumab (Lucentis ${ }^{\circledR}$ ) and bevacizumab (Avastin ${ }^{\circledR}$ ) on human corneal endothelial cells. BMC Ophthalmol. 2018;18(1):316. doi:10.1186/s12886-018-0978-9 
25. Del Amo EM, Urtti A. Rabbit as an animal model for intravitreal pharmacokinetics: clinical predictability and quality of the published data. Exp Eye Res. 2015;137:111-124. doi:10.1016/j. exer.2015.05.003

26. Li T, Balthasar JP. Application of physiologically based pharmacokinetic modeling to predict the effects of FcRn inhibitors in mice, rats, and monkeys. J Pharm Sci. 2019;108(1):701-713. doi:10.1016/j. xphs.2018.10.065

27. Krohne TU, Holz FG, Meyer CH. Pharmakokinetik intravitreal applizierter VEGF-inhibitoren [Pharmacokinetics of intravitreally administered VEGF inhibitors]. Ophthalmologe. 2014;111(2):113-120. doi:10.1007/s00347-013-2932-9

28. Yorston D. Anti-VEGF drugs in the prevention of blindness. Community Eye Health. 2014;27(87):44-46.

29. Volkmann I, Knoll K, Wiezorrek M, Greb O, Framme C. Individualized treat-and-extend regime for optimization of realworld vision outcome and improved patients' persistence. BMC Ophthalmol. 2020;20(1):122. doi:10.1186/s12886-020-01397-x

30. Maniadakis N, Konstantakopoulou E. Cost effectiveness of treatments for diabetic retinopathy: a systematic literature review. Pharmacoeconomics. 2019;37(8):995-1010. doi:10.1007/s40273019-00800-w

31. Azad R, Chandra P, Gupta R. The economic implications of the use of anti-vascular endothelial growth factor drugs in age-related macular degeneration. Indian $J$ Ophthalmol. 2007;55(6):441-443. doi:10.4103/0301-4738.36479

32. Parikh R, Pirakitikulr N, Chhablani J, et al. Comparison of anti-vascular endothelial growth factor use: the United States, the United Kingdom, and Asia-Pacific. Ophthalmol Retin. 2019;3 (1):16-26. doi:10.1016/j.oret.2018.08.002

33. Elshout M, van der Reis MI, Webers CA, Schouten JS. The cost-utility of aflibercept for the treatment of age-related macular degeneration compared to bevacizumab and ranibizumab and the influence of model parameters. Graefes Arch Clin Exp Ophthalmol. 2014;252(12):1911-1920. doi:10.1007/s00417-014-2641-3

34. Feiner L, Barr EE, Shui YB, Holekamp NM, Brantley MA Jr. Safety of intravitreal injection of bevacizumab in rabbit eyes. Retina. 2006;26(8):882-888. doi:10.1097/01.iae.0000230717.85319.f5

35. Inan UU, Avci B, Kusbeci T, Kaderli B, Avci R, Temel SG. Preclinical safety evaluation of intravitreal injection of full-length humanized vascular endothelial growth factor antibody in rabbit eyes. Invest Ophthalmol Vis Sci. 2007;48(4):1773-1781. doi:10.1167/iovs.06-0828
36. Lashay A, Faghihi H, Mirshahi A, et al. Safety of intravitreal injection of stivant, a biosimilar to bevacizumab, in rabbit eyes. J Ophthalmic Vis Res. 2020;15(3):341-350. doi:10.18502/jovr. v15i3.7453

37. Zayit-Soudry S, Zemel E, Barak A, Perlman I, Loewenstein A. Safety of intravitreal bevacizumab in the developing rabbit retina. Retina. 2011;31(9):1885-1895. doi:10.1097/IAE.0b013e31821a88e2

38. Türkcü FM, Alp MN, Türkcü G, Kulaçoğlu S, Kural G. Short term apoptotic activity of intravitreal bevacizumab on rabbit retina. Int $J$ Ophthalmol. 2013;6(6):785-789. doi:10.3980/j.issn.22223959.2013.06.08

39. Chawla R, Nath M, Moksha L, Nag TC, Velpandian T. An experimental study to evaluate safety/toxicity of intravitreal natalizumab. Indian J Ophthalmol. 2018;66(10):1441-1445. doi:10.4103/ijo. IJO_425_18

40. Mazaheri-Khameneh R, Sarrafzadeh-Rezaei F, Asri-Rezaei S, DalirNaghadeh B. Evaluation of clinical and paraclinical effects of intraosseous vs intravenous administration of propofol on general anesthesia in rabbits. Vet Res Forum. 2012;3(2):103-109.

41. Nguyen QD, Brown DM, Marcus DM, et al; RISE and RIDE Research Group. Ranibizumab for diabetic macular edema: results from 2 Phase III randomized trials: RISE and RIDE. Ophthalmology. 2012;119(4):789-801. doi:10.1016/j.ophtha.2011.12.039

42. Wells JA, Glassman AR, Ayala AR, et al.; Diabetic Retinopathy Clinical Research Network. Aflibercept, bevacizumab, or ranibizumab for diabetic macular edema: two-year results from a comparative effectiveness randomized clinical trial. Ophthalmology. 2016;123 (6):1351-1359. doi:10.1016/j.ophtha.2016.02.022

43. Wells JA, Glassman AR, Ayala AR, et al; Diabetic Retinopathy Clinical Research Network. Aflibercept, bevacizumab, or ranibizumab for diabetic macular edema. $N$ Engl J Med. 2015;372 (13):1193-1203.

44. Ahmadieh H, Ramezani A, Shoeibi N, et al. Intravitreal bevacizumab with or without triamcinolone for refractory diabetic macular edema; a placebo-controlled, randomized clinical trial. Graefes Arch Clin Exp Ophthalmol. 2008;246(4):483-489. doi:10.1007/s00417-0070688-0

45. Soheilian M, Ramezani A, Bijanzadeh B, et al. Intravitreal bevacizumab (avastin) injection alone or combined with triamcinolone versus macular photocoagulation as primary treatment of diabetic macular edema. Retina. 2007;27(9):1187-1195. doi:10.1097/ IAE.0b013e31815ec261
Journal of Experimental Pharmacology

\section{Publish your work in this journal}

The Journal of Experimental Pharmacology is an international, peerreviewed, open access journal publishing original research, reports, reviews and commentaries on all areas of laboratory and experimental pharmacology. The manuscript management system is completely online and includes a very quick and fair peer-review system. Visit http://www.dovepress.com/testimonials.php to read real quotes from published authors. 